\title{
Depression among patients with diabetes mellitus in a Nigerian teaching hospital
}

\author{
Bawo Onesirosan James, FMCPsych, FWACP \\ Joyce Ohiole Omoaregba, FWACP \\ George Eze, FWACP
}

Federal Psychiatric Hospital, Benin City, Edo State, Nigeria

Olufemi Morakinyo, FMCPsych, FWACP, MRCPsych Department of Mental Health, University of Benin, Benin City, Nigeria

Objectives. Depression is associated with diabetes mellitus and affects treatment goals negatively. We aimed to determine the prevalence of depression and identify its socio-demographic or clinical correlates among patients with diabetes mellitus attending an out-patient clinic in Nigeria.

Methods. Two hundred consecutively recruited diabetes patients (index group) were compared with a similar number of apparently healthy controls in a cross-sectional survey. In both groups, in addition to obtaining socio-demographic details, depression was diagnosed using the Schedule for the Clinical Assessment in Neuropsychiatry (SCAN), while the Beck Depression Inventory (BDI) was used to assess depression symptom severity.

Results. Sixty (30\%) diabetes patients met a SCAN diagnosis for clinical depression, compared with $19(9.5 \%)$ in the control group. Having a smaller income and more children were significantly correlated with higher depression symptoms on the BDI.

Conclusion. Depression is highly co-morbid with diabetes mellitus. The care of individuals with diabetes mellitus should include the screening and possible treatment for depression in order to achieve and sustain treatment goals.

Depression is twice as likely to occur in individuals with diabetes mellitus (DM) compared with apparently healthy controls.' Prevalence rates vary from $11 \%$ to $60 \%$. Higher rates are observed depending on study setting (clinical v. community), assessment tool (self-report questionnaire v. diagnostic tool) and design (uncontrolled $v$. controlled). ${ }^{1,2}$ Depression negatively affects quality of life, 3,4 treatment outcome ${ }^{5}$ and medication adherence ${ }^{6}$ of patients with DM. Female gender, low socio- economic class and the presence of other physical illnesses are associated with an increased likelihood of depression in patients with diabetes. 2,7

In Nigeria, crude prevalence estimates for DM are about 7\%; with an estimated 10 million people suffering from the disease. ${ }^{8}$ The prevalence in sub-Saharan Africa is expected possibly to triple by 2030, ${ }^{9}$ making it a cause for concern of not only health professionals but also policy makers as they initiate strategies to tackle it. Studies enumerating the prevalence of depression among patients with DM in Nigeria, not to mention sub-Saharan Africa, are few. ${ }^{3,10-12}$ Studies employing the use of rating scales $^{10,11}$ or diagnostic instruments ${ }^{3,12}$ have been limited by small sample sizes.

Depression is still largely unrecognised by physicians managing patients with DM. We aimed to determine the prevalence of depression among patients with DM in Nigeria employing a moderate sample. Also, we sought to determine the psychosocial impact of the disease in a developing country.

\section{Materials and methods}

\section{Study setting and participants}

The study was conducted at the Endocrinology Clinic of the University of Benin Teaching Hospital (UBTH), Benin City, Nigeria, from March to May 2009. The UBTH is a tertiary referral health care facility that provides specialist endocrinology services to a population of approximately 2.5 million people. Patients (who comprised the index group) were aged between 20 and 64 years, had been diagnosed with DM according to World Health Organization (WHO) criteria for at least 1 year, and were without a co-morbid illness that impaired their ability to understand the nature and purpose of the study. A control group (without a history of DM) matched for age ( \pm 2 years), sex and educational status were recruited from the staff of three local government areas (Ikpoba-Okha, Oredo and Egor) that comprise the areas of Benin City where most of the patients resided.

\section{Measures}

We administered the following three documents:

- A socio-demographic questionnaire designed by the authors to capture socio-demographic variables such as age, sex, and marital, employment and educational status. In the index 
group, clinical details such as type of diabetes, duration of illness, modality of treatment and presence of other physical co-morbidities were either extracted or corroborated from patient records.

- The depression module of the Schedule for the Clinical Assessment in Neuropsychiatry (SCAN) ${ }^{13}$ to diagnose depression. Recorded data were entered into a computer algorithm that generated a diagnosis according to the International Classification of Diseases (ICD-10) criteria. The SCAN has good psychometric properties and has been used in populations in general hospital and psychiatric settings in Nigeria. ${ }^{14}$

- The Beck Depression Inventory (BDI), ${ }^{15}$ a 21 -item self-report questionnaire for the measurement of depression and its severity. Each item has a score-range of $\mathrm{O}$ - 3; item scores are added to determine the intensity of depression. A minimum total score of 10 is required to identify subjects with significant symptoms. A score range of $10-18$ indicates mild/moderate depression; 19 - 29 moderate/severe; and 30 - 63 extremely severe depression. The BDI has been standardised and widely used in Nigeria. ${ }^{15}$

The SCAN and the BDI were translated into pidgin English, which is the lingua franca in the cosmopolitan city of Benin, using the method of back translation. One of the authors administered the questionnaires to respondents to aid consistency.

\section{Ethics}

The ethics review committee of UBTH reviewed and approved the study protocol.

\section{Procedure}

Patients attending scheduled clinic visits, who satisfied the inclusion criteria, were approached by one of the authors. The nature and purpose of the study was explained and full confidentiality assured. Written informed consent was subsequently obtained from patients who agreed to participate. The socio-demographic questionnaire and BDI were self-administered among literate patients. In illiterate patients, statements on the socio-demographic questionnaire and the BDI were read out, either in English or in the translated pidgin English format. Subsequently, the depression module of the SCAN was administered by one of the authors to diagnose the presence of depression. A similar procedure was employed among the apparently healthy controls.

\section{Data analysis}

Data were analysed using the Statistics for Social Science (SPSS) software, version 11. Descriptive statistics were used to summarise the data. Comparisons of categorical and continuous variables were done using the chi-square and ttests respectively. Relationships between continuous variables were conducted using the Pearson correlation analyses.

\section{Results}

Over the study period, 211 patients satisfied the study's inclusion criteria and were approached, of whom 200 consented to participate in the study $(94 \%$ participation rate). The same number (200) of apparently healthy controls was recruited from personnel of 3 local governments. The mean age and SD of the diabetes patients (index group) was $47.1 \pm 9.6$ years. This was comparable with that of the local government staff (control group) of $46.4 \pm 9.2$ years $(t=0.88, d t=398, p=0.379)$. In the index group, $54 \%$ were female, $83.5 \%$ were married, $66.5 \%$ were employed, and $97.5 \%$ were Christian. Respondents in the index group had on

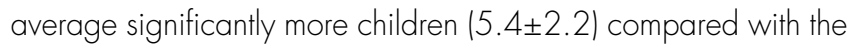
average number of $2.9 \pm 2.2$ among the control group $(t=11.28$, $d f=398, p<0.0011$. Furthermore, respondents in the index

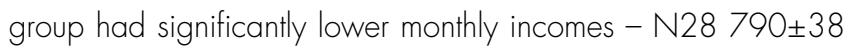
264 compared with N68 900 \pm 30386 of the control group $(t=-11.61, d f=398, p<0.001)$.

In the index group, a majority were being managed for type 2 DM, and most (69\%) reported having other physical co-morbidities. The most common (68.5\%) were cardiovascular (hypertension, ischaemic heart disease and cerebrovascular incidents). Most (64.5\%) of the patients had been diagnosed with diabetes for less than 5 years. The average duration of diabetes was $5.2 \pm 5.2$ years. Approximately $20 \%$ of the patients had a family history of diabetes.

Sixty $(30 \%)$ respondents in the index group met a SCAN diagnosis for a depressive disorder according to the ICD-10, which was significantly higher than the proportion of $9.5 \%$ who met a SCAN diagnosis of depression in the control group $\left(\chi^{2}=26.51, d f=1, p<0.001\right)$. Of those in the index group who had a depressive disorder, 31 (51.7\%) met the SCAN criteria for mild depression, 22 (36.7\%) were moderately depressed, and the remainder had severe depression. A comparison of some socio-demographic and clinical characteristics of the index group with the presence or absence of a SCAN diagnosis of depression is shown in Table I. 


\begin{tabular}{|c|c|c|c|c|}
\hline Socio-demographic variables & Depression present & Depression absent & $\chi^{2}$ & $p$ \\
\hline \multicolumn{5}{|l|}{ Age } \\
\hline $20-44$ years & 30 & 65 & 0.215 & 0.647 \\
\hline $45-65$ years & 30 & 75 & & \\
\hline \multicolumn{5}{|l|}{ Sex } \\
\hline Male & 23 & 69 & 2.028 & 0.167 \\
\hline Female & 37 & 71 & & \\
\hline \multicolumn{5}{|l|}{ Marital status } \\
\hline Married & 50 & 117 & 0.002 & 0.559 \\
\hline Not married (single/separated/divorced) & 10 & 23 & & \\
\hline \multicolumn{5}{|l|}{ Employment status } \\
\hline Employed & 39 & 94 & 0.087 & 0.445 \\
\hline Unemployed & 21 & 46 & & \\
\hline \multicolumn{5}{|l|}{ Number of children } \\
\hline$<4$ & 29 & 100 & 2.251 & 0.078 \\
\hline$\geq 4$ & 31 & 40 & & \\
\hline \multicolumn{5}{|l|}{ Family history of diabetes? } \\
\hline Yes & 14 & 26 & 0.446 & 0.278 \\
\hline No & 16 & 114 & & \\
\hline \multicolumn{5}{|l|}{ Other physical co-morbidity? } \\
\hline Yes & 41 & 97 & 0.018 & 0.570 \\
\hline No & 19 & 43 & & \\
\hline \multicolumn{5}{|l|}{ Monthly income/allowance } \\
\hline$<N 7500$ & 24 & 40 & 2.251 & 0.078 \\
\hline >N7 500 & 36 & 100 & & \\
\hline \multicolumn{5}{|l|}{ Years of formal education } \\
\hline$<12$ years & 49 & 109 & 0.705 & 0.343 \\
\hline$>12$ years & 11 & 31 & & \\
\hline
\end{tabular}

On the BDI, approximately $77(39.5 \%)$ respondents in the index group had BDI scores $>10$, compared with $27(13.5 \%)$ in the control group. The mean BDI score of $10.77 \pm 8.97$ in the index group was significantly higher than the score of $4.74 \pm 4.82$ in the control group ( $t=8.37, \mathrm{df}=398, p<0.001)$. Monthly income/ allowance as well as number of children was significantly and negatively correlated with $\mathrm{BDI}$ scores. There was a positive correlation between age, duration of diabetes and BDI scores; however, this association was not significantly correlated (Table II).

\section{Discussion}

The prevalence of depression (30\%) among patients with DM in this study using a diagnostic instrument, was much higher than that reported in an earlier study $(9.5 \%)$ conducted in this environment and employing similar methodology. ${ }^{3}$ Although the mean age of the population in the study by lssa et al. ${ }^{3}$ was similar to that in our study, our sample had a higher representation of females. Anderson and his colleagues ${ }^{2}$ observed in their metaanalysis that depression was more likely to occur in women with diabetes than in men. This reason alone may not be sufficient to

Table II. Correlation between some socio-demographic and clinical characteristics and BDI score

\begin{tabular}{lcc}
\hline & \multicolumn{2}{c}{ BDI score } \\
Socio-demographic/clinical variables & Pearson co-efficient $(r)$ & 0.708 \\
\hline Age & 0.027 & $0.003^{*}$ \\
Income & -0.207 & $0.010^{*}$ \\
Number of children & -0.183 & 0.445 \\
Duration of diabetes & 0.054 & \\
*Statistically significant. & &
\end{tabular}


explain our finding; perhaps a high proportion of the index group reporting having other physical co-morbidities may account for this. Furthermore, the prevalence of depression symptoms using a cut-off score of 10 and above on the BDI was 39.5\%, which was also higher than the range of 20 - 31\% observed in other studies in the country employing the use of rating scales alone. ${ }^{10-12}$

We found a significant correlation between earning power, having more children and depression symptom severity as measured by the $\mathrm{BDI}$. DM is a chronic physical disorder that requires lifestyle alterations and medication adherence for its successful treatment. Individuals with low earning power face the twin burdens of paying for health care, which in Nigeria is largely out-of-pocket, and meeting the needs of their children. Our study design does not permit interpretations as to causality or the temporal relationships between depression, low earning power and larger number of children; however, it may be safe to say that the presence of these characteristics in persons with diabetes could be a pointer to the presence of depressive symptoms, especially in individuals with poor glycaemic control and medication adherence.

Although diabetes patients who were female, married, or had less than 12 years of education were more likely to have a SCAN diagnosis of depression, we found no statistically significant associations. Our finding contrasts the report from Texas, USA, where female gender and a lower duration of formal education were predictors of depression.?

Our study is not without limitations. Firstly, it was conducted at one centre, which limits the generalisation of our findings. Secondly, we did not control for other mental illnesses such as anxiety disorder which are co-morbid with depression in DM. Thirdly, we did not determine the validity of the translated questionnaires as well as the reliability of the self- or interviewer-administered forms.

\section{Conclusion}

$D M$ is expected to assume pandemic proportions in sub-Saharan Africa. ${ }^{10}$ Our study further confirms the impression that depression is highly co-morbid with the disease. The negative effect of depression on achieving good glycaemic control means that physicians need to screen for and manage this disorder to improve not only the quality of life of diabetes patients but also reduce overall treatment costs, which are generally unaffordable by most individuals with the disease.

\section{References}

1. Ali S, Stone MA, Peters IL, Davies MJ, Khunti K. The prevalence of co-morbid depression in adults with Type 2 diabetes: a systematic review and meta-analysis. Diabet Med 2006; 23: 1 165-1 173.

2. Anderson RJ, Clouse RE, Freedland KE, Lustman PJ. The prevalence of comorbid depression in adults with diabetes. Diab Care 2001; 24: 1069-1076.

3. Issa BA, Yussuf AD, Baiyewu $O$. The association between psychiatric disorders and quality of life of patient with diabetes mellitus. Iran J Psychiatry 2007; 2: 30-34.

4. Jacobson AM, de Groot M, Samson JA. The effects of psychiatric disorders and symptoms on quality of life in patients with type I and type II diabetes mellitus. Qual Life Res 1997; 6: 11-20.

5. Lustman PJ. Clouse RE. Depression in diabetic patients: the relationship between mood and glycaemic control. J Diab Compl 2005; 19: 113-122.

6. Gazmararian JA, Ziemer DC, Barnes C. Perception of barriers to self-care management among diabetic patients. Diab Educ 2009: 35: 778-788.

7. Mier N, Bocanegra-Alonso A, Zhan D, et al. Depression and diabetes in a bi-national border population. J Am Board Fam Med 2008; 21 : 224-233.

8. Erasmus RT, Fakeye T, Olukoga $T$, et al. The prevalence of diabetes in a Nigerian population. Trans R Soc Trop Med Hyg 1989; 83: 417-418.

9. Nyenwe EA, Odia OJ, Ihekwaba AE, Ojule A, Babatunde S. Type 2 diabetes in adult Nigerians: a study of its prevalence and risk factors in Port Harcourt, Nigeria. Diab Res Clin Pract 2003; 62: 177-185.

10. Wild S, Roglic G, Green A, Sicree R, King H. Global prevalence of diabetes estimates for the year 2000 and projections for 2030. Diab Care 2004; 5: 1047 1053

11. Akinlade KS, Ohaeri JU, Suberu MA. The psychological condition of a cohort of Nigerian diabetic subjects. Afr J Med Med Sci 1996; 25: 61-67.

12. Mosaku KS, Kolawole B, Mume C, Ikem R. Depression, anxiety and quality of life among diabetic patients: a comparative study. J Nat Med Assoc 2008; 100: 73-78.

13. Coker AO, Ohaeri JU, Lawal RA, et al. Specific psychiatric morbidity among diabetics at a Nigerian General Hospital. East Afr Med J 2000; 77: 42-45.

14. Wing JK, Babor T, Brugha T, et al. SCAN: Schedule for clinical assessment in neuropsychiatry. Arch Gen Psychiatry 1990; 47: 589-593.

15. Eze UE. Depression and suicidality among HIV/AIDS out-patients in Benin City. FMCPsych dissertation, National Postgraduate Medical College of Nigeria, Lagos, 2008: 58 .

16. Beck AT, Ward CH, Mendelson M, Mock J, Erlbaugh J. An inventory for measuring depression. Arch Gen Psychiatry 1961; 4: 561-571.

17. Awaritefe A. The Beck Depression Inventory in relation to some commonly used tests in Nigeria. Nig J Basic App Psychology 1988; 1: 23-28. 